In any case it is likely to be some considerable time before Irish obstetricians will be found who are willing to carry out abortion procedures. Whatever the outcome of these uncertainties, there is no immediate prospect of Irish psychiatrists finding themselves embroiled in the assessment of women seeking abortion except in selected cases before the courts: and as long as the option of seeking abortion abroad, presently utilised by at least 4,000 women annually, continues to be available.

T. J. FAHY, Clinical Science Institute, University College Galway, Ireland

Editorial note. The author recently concluded a ten year spell of membership of the Irish Medical Council.

\section{Working together for victims and perpetrators of emotional, physical and sercual abuse}

Sir: Thanks to the College for organising this inter-sectional conference which enabled participants to gain a broader appreciation of this multifaceted topic. Despite time being allocated equally to the four College sections, the main focus of discussion tended to be children and sexual abuse at the expense of acknowledging the tremendous impact of emotional, physical and financial abuse on vulnerable adults. This possibly mirrors media, public interest and awareness.

Child psychiatrists have pioneered the way of enabling children's evidence to be heard, but it appears that now they wonder if the disadvantages outweigh the benefits. Concern was expressed that legal requirements took precedence over treatment needs, and that the legal process further traumatised victims. This, together with the tensions experienced in balancing duties towards both victims and perpetrators, led to some calls for 'decriminalisation' of abuse.

While understanding the reasons behind these views, I feel they represent a denial of the facts and a betrayal of the right of children and vulnerable adults to the same legal protection as anyone else. It would be preferable to identify specific problems in the legal process, and to seek solutions to these enabling the system more adequately to function, thus benefiting both perpetrators, victims and their families. The British legal system has a long conservative tradition and modifications are not easily incorporated, but as Spencer (1988) said, "Tradition can be good or bad and if a tradition blocks a sensible, humane and necessary reform it is the tradition which should be reconsidered, not the proposed reform".

Community care requires that all community facilities are accessible, including the law. There are signs that we are not alone in our concern. The Home Office have commissioned research into witnesses with learning disabilities, and the Bar Council has proposals for a network of barristers experienced with the learning disabled. In her conference address, The Right Hon Lady Justice Butler Sloss emphasised the need for dialogue between psychiatrists and lawyers.

Could the College share our concerns with our legal colleagues and develop a joint view of the best way forward?

SPENCER, J. (1988) Child witnesses, a case for legal reform. In Division of Criminological and Legal Psychology. 13.

JANE E. BRYLEWSK, Oxfordshire Learning Disability NHS Trust, Slade House, Horspath Driftway, Headington, Oxford OX3 7JH

\section{Suicide in farmers}

Sir: Mid-Wales Coroner, Mr John Hollis referred to "almost epidemic proportions" of suicides among farmers after returning three such verdicts the same day at inquests in Brecon (The County Times \& Express \& Gazette, 1994)

While a trainee in Shropshire I saw two similar cases who had survived attempted suicide by the use of shotguns. Their nonfatal injuries were the result of difficulty encountered in firing such guns into the mouth. To accommodate the length of the barrel, it is often necessary to lean to one side to activate the trigger. The discharge is thus directed laterally, exiting through non-vital extra-cranial tissue in the zygomaxillary region and missing the adjacent temporal lobe; (an injury well described in specialised surgical texts). Following emergency surgery, psychiatric in-patient management achieved full recovery from severe depressive episodes in both cases. 